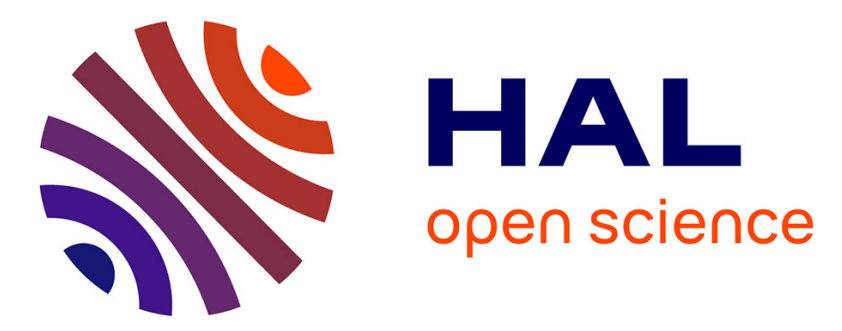

\title{
The management of cohesion in written narratives in students with specific language impairment: Differences between childhood and adolescence
}

Monik Favart, Anna Potocki, Lucie Broc, Pauline Quemart, Josie Bernicot, Thierry Olive

\section{To cite this version:}

Monik Favart, Anna Potocki, Lucie Broc, Pauline Quemart, Josie Bernicot, et al.. The management of cohesion in written narratives in students with specific language impairment: Differences between childhood and adolescence. Research in Developmental Disabilities, 2016, 59, pp.318-327. 10.1016/j.ridd.2016.09.009 . hal-01950077

\section{HAL Id: hal-01950077 \\ https://hal.science/hal-01950077}

Submitted on 5 Dec 2019

HAL is a multi-disciplinary open access archive for the deposit and dissemination of scientific research documents, whether they are published or not. The documents may come from teaching and research institutions in France or abroad, or from public or private research centers.
L'archive ouverte pluridisciplinaire HAL, est destinée au dépôt et à la diffusion de documents scientifiques de niveau recherche, publiés ou non, émanant des établissements d'enseignement et de recherche français ou étrangers, des laboratoires publics ou privés. 


\title{
The management of cohesion in written narratives in students with specific language impairment: Differences between childhood and adolescence
}

\author{
Monik Favart ${ }^{\mathrm{a}, *}$, Anna Potocki ${ }^{\mathrm{a}}$, Lucie Broc ${ }^{\mathrm{b}}$, Pauline Quémart ${ }^{\mathrm{a}}$, \\ Josie Bernicot ${ }^{\mathrm{a}}$, Thierry Olive ${ }^{\mathrm{a}}$ \\ a Centre de Recherches sur la Cognition et l'Apprentissage, UMR 7295, University of Poitiers, France \\ b Bases, Corpus, Langage, UMR 7320, ESPE, University of Nice Sophia Antipolis, France
}

\section{A R T I C L E I N F O}

\section{Article history:}

Received 3 February 2016

Received in revised form 13 July 2016

Accepted 13 September 2016

Number of reviews completed is 2

\section{Keywords:}

Children and adolescents with SLI

Narrative writing

Communicative situation

Cohesion devices

\begin{abstract}
A B S T R A C T
The goal of this study was to investigate the management of cohesion by children and adolescents with specific language impairment (SLI) when writing a narrative in a communicative situation. Twelve children with SLI (from 7 to 11 years old) and 12 adolescents with SLI (from 12 to 18 years old) were chronological age-matched with 24 typically developing (TD) children and 24 TD adolescents. All participants attended mainstream classes: children in elementary schools and adolescents in middle and high schools. Analyses of cohesion focused on both density and diversity of connectives, punctuation marks and anaphors. Results attested that children with SLI were greatly impaired in their management of written cohesion and used specific forms previously observed in narrative speech such as left dislocations. By contrast, and not expected, the management of written cohesion by adolescents with SLI was close to that of their TD peers. The communicative writing situation we set up, which engaged participants to take into account the addressee, also made possible for adolescents with SLI to manage cohesion in writing.
\end{abstract}

(c) 2016 Elsevier Ltd. All rights reserved.

Specific language impairment (SLI) is a developmental disorder of language acquisition that occurs in the absence of mental retardation, neurological damage, hearing deficits, or environmental deprivation (Bishop, 1992a, 1992b; Leonard, 2014). Language difficulties are heterogeneous and appear essentially at the phonological, morphosyntactic, and semantic levels. These difficulties generally remain through adolescence (Snowling, Bishop, \& Stothard, 2000; van Weerdenburg, Verhoeven, Bosman, \& van Balkom, 2011). Children with SLI also are at risk for developing problems with the acquisition of written language. For instance, children with SLI aged 9; 5 years old produce more spelling errors when composing a letter to their best friend than the TD age-matched participants (Williams, Larkin, \& Blaggan, 2013; see also Cordewener, Bosman, \& Verhoeven, 2012). Broc, Bernicot, Olive, Favart, and Quémart (2013) also pointed out the lexical spelling difficulties of participants with SLI aged from 7 to 18 years old. They however observed that these difficulties were lower in a narrative communicative situation than in an evaluative task, i.e. a dictation of isolated words. In this study, each participant composed a narrative with the presence of the experimenter throughout the entire writing process. The experimenter orally delivered the instruction: participants were asked to write a story about a personal event and to make it as precise as possible, so that she (the researcher) could really understand what happened. In such a situation, performances in the management of lexical spelling by adolescents with SLI (aged from 12 to 18 years old) were not significantly different from performances of their TD age-matched peers.

\footnotetext{
* Corresponding author at: CeRCA (UMR 7295), Université de Poitiers, MSHS Bât. A5, 5 rue Théodore Lefebvre, TSA 21103, 86000 Poitiers, France.

E-mail address: monik.favart@univ-poitiers.fr (M. Favart).
} 
The aim of the present study was to investigate the ability of children and adolescents with SLI to manage cohesion in written narratives. Cohesion ensures the structuration of the text as a whole and is carried out using specific linguistic devices: connectives, punctuation marks and anaphors. These devices play a major role in writing, drawing up relationships between ideas generated during text planning. In this way the devices enable the addressee to establish the representation of the text as a whole and contribute to textual coherence (see Apotheloz, 1989; Favart \& Passerault, 1999 for connectives; Passerault, 1991 for punctuation marks; and Reichler- Beguelin, 1988 for anaphors).

\section{The use of cohesion devices during writing acquisition of typically developing children}

Connectives, punctuation marks and anaphors are linguistic devices that carry specific functions in discourse processing. As a syntactic function, they link together textual segments, and as semantic and procedural functions, they provide instructions to the addressee to accurately integrate textual content. Thus, the main role of cohesion devices is to operate as processing instructions. They carry a procedural core meaning, in that they instruct the addressee how to connect or separate discourse events and so helping him/her to draw up an accurate representation of the overall discourse (Louwerse \& Mitchell, 2003). Karmiloff and Karmiloff-Smith (2003) pointed out the close connection between the achievement of textual coherence and the accurate management of cohesion in language acquisition.

The study of connectives in the course of writing acquisition requires specific focus on the word and (see Favart \& Passerault, 1999 for a review). Using and is very convenient for young students as it can express single-handedly a substantial variety of relations. Its huge frequency in children's written stories attests to an immature local mode of planning, carried out according to step-by-step processing. The connective and is systematically repeated and triggered between two cycles of content generation to support the substantial burden caused within working memory by the writing activity. The chronological connectives: puis, après, ensuite (after, then) can be used the same way as and between two generated ideas to sustain the writing activity and to avoid children to express more sophisticated relationships.

From the age of 10 years, the decreasing load of handwriting and orthographic coding enables children to devote more cognitive resources to linguistic choices (Berninger \& Swanson, 1994; McCutchen, 1996). At the same time, children gradually gain a structured knowledge of the system of connectives (Karmiloff-Smith, 1985, 1992). This enables them to diversify relationships using connectives which are more and more consistent with the textual structure.

Specific connectives can be selected to translate more appropriately narrative relationships and gradually increase coherence in written stories. Favart and Passerault (1995) showed that the density of and (related to the total number of used connectives) decreased across elementary school, mainly in grade five (i.e., in 10 years old children). The undifferentiated connective then gave way to more diversified ones: mais (but), alors (then); temporal connectives quand, lorsque, soudain, tout à coup (when, while, suddenly); and causal connectives car, parce que (since, because).

The punctuation marks used by children when writing stories are mostly, even exclusively, periods and commas. From the age of 7 years, children use the period predominantly to delimit blocks of information, just as the word and operates (Favart \& Passerault, 2000). The period and the connective and function competitively, as well as in an additional way, to pace the repetition of cycles of content generation. The use of the comma emerges in third grade (i.e., at the ages between 8 and 9 years old). Such a diversification opens up new possibilities but simultaneously creates new problems (Fayol, 1997) because third graders concurrently use periods and commas, since they are not yet aware of the value of their respective break (period > comma). Finally, the use of the comma gradually increases during fourth and fifth grades, and it progressively becomes appropriate. Just as with connectives, the use of periods and commas changes at the age of 10 years old, i.e., in the last grade of elementary school. Periods, quasi-exclusive until fourth grade, were joined in fifth grade by increasing use of commas, particularly within the description of detailed information. It is not before the age of 14 years that children's use of punctuation marks can be determined at a textual level in order to appropriately clarify the textual content for the addressee (Schneuwly, 1988).

Specifically, anaphors are used to refer to a previously mentioned referent (Gernsbacher, 1989), predominantly as nominalizations paired with definite articles or pronouns. They enable the addressee to establish relations between textual sections, just as connectives (Fraser, 1999). Connectives additionally specify the nature of the relationships to the addressee (Stoye, 2013), and their interpretation is in a large part determined by the addressee's mental representation of events (Moeschler, 2002). Punctuation marks build up a hierarchical system according to the strength of the break they induce between textual units. They also serve to organize textual sections in order to enable the accurate construction of the whole text meaning.

Developmental studies conducted in typically developing children attested that at about the age of 10 years, children can manage accurately anaphors in written narratives (Bartlett \& Scribner, 1982; Decool-Mercier \& Akinci, 2010; Pellegrini, Galda, \& Rubin, 1984). This skill develops both quantitatively (Hickmann, 2004) and qualitatively (Rutter \& Raban, 1982) until the end of elementary school. Children then can accurately use various sorts of pronouns (e.g., personal, relative, demonstrative) and juggle with proper names, or nominal substitutions with definite articles, to maintain reference if necessary. At the age of 10 years, children also can accurately manage referential ambiguity when writing stories from pictures that displayed two characters of the same gender (Favart \& Passerault, 1996). However, Lambert (2003) pointed out that the referential upholding by pronouns still could be problematic at the end of elementary grades. Thus, the acquisition and the management of cohesion devices in text composition is quite a laborious process, even in typically developing children (see Favart, 2005 for a review).

\section{Narrative writing abilities in students with SLI}

Only a few studies have investigated writing abilities in participants with SLI, and most of these studies were conducted with English native speakers. Moreover, no study has investigated participants' overall management of cohesion in writing. The few available results demonstrate that stories written by participants with SLI are shorter than those of chronologically age-matched participants (see Dockrell, Lindsay, Connelly, \& Mackie, 2007; Dockrell, Lindsay, \& Connelly, 2009; Fey, Catts, Proctor-Williams, Zhang, \& Tomblin, 2004; Mackie \& Dockrell, 2004; Williams et al., 2013). According to Dockrell and Lindsay (2000), teachers report that linguistic coding is specifically difficult to manage during writing for students with SLI. Their selection of linguistic units appears to be hindered and reduced to a minimum. But these findings mainly focused on grammatical coding. So when writing stories, 9- to 12-year-old participants with SLI were attested to produce more grammatically unacceptable complex T-Units (i.e., including both a main and a subordinate clause) than age-matched children (Gillam \& Johnston, 1992). The grammatical complexity or basic sentence structure also was lower, and/or they produced more grammatical errors than their chronological-age peers (Dockrell et al., 2007; Fey et al., 2004; Mackie \& Dockrell, 2004; Scott \& Windsor, 2000). The few research 
studies analyzing narrative quality confirm that children with SLI have a poorer writing quality than what would be expected at their age, even if it could improve between second and fourth grade (Fey et al., 2004), and a high level of literacy impairment (Freed, Adams, \& Lockton, 2011).

Most of the studies focusing on narrative cohesion have been conducted in speech. Both causal and temporal connectives are produced regularly in typical children's narrative speaking from the age of 7 or 8 years (Kern, 2000). Hilaire-Debove and Roch (2012) analyzed the use of causal and temporal connectives in children with SLI aged from 7 to 12 years old. They observed that participants with SLI produced a series of sentences regularly linked with the connective and or with chronological connectives ( $87,6 \%$ of the occurrences) and only $10,4 \%$ of temporal or causal connectives. Moreover, they did not notice any improvement in connectives diversification between the ages of 7 and 12 years. According to Bernard-Barrot and Géhard (2003), narrative speaking of children with SLI includes as many connectives as typically developing children's but makes use of less differentiated ones.

Hilaire-Debove and Roch (2012) also analyzed the use of pronouns (both their maintenance and reintroduction) in children with SLI aged from 7 to 12 years old. They noticed the equal use of pronouns and of determiner + noun device. Children with SLI still use the latter form until the age of 11 years, whereas its use is marginal after the age of 5 years in TD children. Children with SLI also differ from TD children in their use of specific constructions such as left dislocations (De Weck \& Jullien, 2013; Jullien, 2008). Such dislocations are said to promote accessible referents to the status of topic by extracting the lexical unit from the clause to its left periphery and then co-indexing this referent with a pronoun. They are expressed such as C'est NP qui=It's NP who (i.e., C'est un garçon qui le pousse: It's a boy who pushes him). These dislocations are visible in oral production of participants with SLI between the ages of 4 and 11 years, but they decline in children from the ages of 10 to 11 years, who tend to perform similarly to typical children (Jullien, 2008). More precisely, in the storytelling on the basis of pictures proposed by De Weck and Jullien (2013), the production of dislocations was significantly higher in children with SLI than in TD children only at the ages between 6 and 7 years. The children with SLI produced more left dislocations and fewer presentational constructions than their TD peers. Accordingly, a left dislocation seems to reflect more a morphosyntactic difficulty rather than a pragmatic difficulty. It could be used to avoid the production of more complex structures and therefore enable the children to express the reference at a lesser cognitive cost (De Cat, 2004).

In narrative composition, only one study has yet coded punctuation in written products of children with SLI. Bishop and Clarkson (2003) asked participants aged 7.5 to 13 years to compose narratives on the basis of five pictures. A global score of intelligibility with a 4-point scale assessed accuracy of the written output in terms of spelling and punctuation. Results showed that this intelligibility index was the most sensitive indicator of language impairment, with 16 of the 28 children scoring more than $1 S D$ below the control mean. But punctuation and spelling carry very different functions in written discourse production. So, on the basis of this global intelligibility index, we cannot draw any conclusion about the management of the lone system of punctuation as a specific indicator of cohesion. These previous results, however, still indicate the impact of oral difficulties on narrative composition. They evidence the lower performance of children with SLI compared to typically developing chronological-age peers in this activity and their limits in text generation processing.

Little is known however about the development of abilities of participants with SLI to manage cohesion in written composition. Only one study analyzed this aspect through childhood and adolescence. Dockrell et al. (2009) longitudinally examined the writing performance of 58 students from 8 to 16 years old. They concluded that, until the age of 16 years, participants continued to experience problems with literacy. Moreover, students' writing skills, such as handwriting fluency, sentence structure, and spelling, decreased relative to standardized norms from the age of 11 years. According to Dockrell et al. (2009), for typically developing children, increasing language and literacy skills can support later development of writing; conversely, for those with persistent difficulties, such resources cannot be available.

\section{The present study: goals and hypotheses}

The present study investigated the management of the three systems of cohesion devices in participants with SLI when writing a narrative. The study was conducted in two age groups: children and adolescents. The performance of the participants with SLI was compared to the one of chronologically age-matched typically developing (TD) students. All participants attended ordinary classes and were taught according to instructions of the French curriculum. Children attended elementary school, and adolescents attended middle and high schools. We compared the performance of the group with SLI to the performance of the TD group at each age as well as the performance of the two age groups within each type of group.

We expected participants with SLI to encounter difficulties in the management of each system of cohesion devices compared to their TD peers. We assumed that their high level of literacy impairment (Freed et al., 2011) and their recurrent difficulties in linguistic coding (Dockrell \& Lindsay, 2000) would affect their generation of cohesion devices. Accordingly, their capacity to choose sufficient and adequate marks to express textual relationships should be lower than that of their TD peers. In that way, we expected students with SLI to use both less numerous and less differentiated connectives than TD students, and that they would use a higher density of and and/or less differentiated connectives (see Favart \& Passerault, 1995). This prediction also relied on oral skills of participants with SLI, who show a recurrent use of the connective and as well as a lack in diversification compared to TD children (De Weck \& Rosat, 2003; Hilaire-Debove \& Roch, 2012).

As regards punctuation marks, we expected the periods to be used predominantly as soon as children with SLI could implement the punctuation system in their composition. The main difference between the two groups might preferentially affect the use of the comma, which only develops at the end of elementary school in TD students' narrative texts (Favart \& Passerault, 2000).

As regards referential expressions, based on oral production, we expected participants with SLI to mainly use nominal repetitions (HilaireDebove \& Roch, 2012). Unlike TD participants, we expected them to also use specific mentions such as left dislocations (De Weck \& Jullien, 2013; Jullien, 2008). Moreover, the differences observed during childhood between participants with SLI and TD participants should carry on and even be larger in adolescents. According to Dockrell et al. (2009), difficulties of students with SLI in language generation and sentence structuring decrease relative to standardized norms from the age of 11 years. In agreement with Berninger and Swanson's (1994) developmental model of composition and with McCutchen's (1996) capacity theory of writing, Dockrell et al. (2009) explained that the persistent difficulties of adolescents with SLI in language and literacy skills cannot save sufficient resources to support their writing development. In the TD group, we expected to observe better performances in each aspect of written cohesion abilities in adolescents than in children. An accurate management of the three systems of cohesion devices can work in narrative writing at the end of elementary school. The TD adolescents all attended middle and high schools, so they should be able to diversify more than children the marking of narrative relations by connectives and anaphors. A regular use of both punctuation marks should be effective only in this group. 
Table 1

Numbers of participants, mean ages (standard deviations) and gender breakdowns in children and adolescents with SLI and in typically developing children and adolescents (TD).

\begin{tabular}{llll}
\hline Participants & $N$ & Mean age (SD) & Range \\
\hline SLI $\quad$ Children & 12 & $8.94(1.12)$ & 7.66 to 11.00 \\
$\quad$ Adolescents & 12 & $14.33(1.77)$ & 12.08 to 17.50 \\
TD & & & 10 boys $/ 2$ girls \\
$\quad$ Children & 24 & $8.85(1.07)$ & 7.50 to 11.16 \\
$\quad$ Adolescents & 24 & $14.05(1.41)$ & 12.25 to 17.68 \\
\hline
\end{tabular}

To sum up, the first aim was to investigate the management of cohesion in children and adolescents with SLI by comparing their performance to that of age-matched TD students. We expected the management of connectives, punctuation marks, and anaphors to be weaker in participants with SLI than in TD participants, in both age groups and at both levels of density and diversity. The second aim was to compare, in both SLI and TD groups, the management of cohesion in children and adolescents. We expected a weaker management of cohesion in children than in adolescents. Moreover, the differences observed during childhood between SLI and TD participants should carry on and even be larger in adolescents.

\section{Method}

\subsection{Participants}

The sample included a total of 24 participants with SLI. Twelve were children (10 boys and 2 girls) aged between 7 and 11 years old, and 12 were adolescents ( 7 boys and 5 girls) aged between 12 and 18 years old.

Children and adolescents with SLI had been diagnosed by the Centre Référent des Troubles du Langage (Referral Center for Language Disorders) of the Henri Laborit Hospital in Poitiers, France. The diagnosis was based on a medical assessment as well as neuropsychological and psycholinguistic testing. Participants with SLI attested a discrepancy between their level of oral language and nonverbal abilities.

The inclusion criterion of these participants with SLI was a score of at least 1.25 SD below the mean scores on the following standardized language tests:

- For 7-year-old participants, the Bilan Informatisé du Langage Oral au cycle 2 (BILO-2, [Computerized Assessment of Oral Language for 5-7 years old children], Khomsi, Khomsi, \& Pasquet, 2007) and the Nouvelles Epreuves pour lExamen du Langage (N-EEL, [New Tasks for the Language Assessment], Chevrie-Muller \& Plazza, 2001).

- For participants at the age of 8 years and older, the Bilan Informatisé du Langage Oral 3 et au Collège (BILO-3C, [Computerized Assessment of Oral Language for 8-10 years old children, and at middle school], Khomsi, Khomsi, Pasquet, \& Parbeau Guéno, 2007) and the Batterie Langage Oral et Écrit, Mémoire, Attention (L2MA, [Test Oral and Written Language, Memory, Attention], Chevrie-Muller, Simon, \& Fournier, 1997)

The language comprehension abilities of the participants with SLI fell within normal limits, and they showed no cognitive impairment, with a score greater than 80 on the Wechsler Intelligence Scale for Children, 3rd Edition (WISC-III, Wechsler, 1996).

The participants with SLI were matched to a group of typically developing (TD) participants, according to age, gender, and the parental social economic status. Twenty-four typically developing children were matched to the children with SLI (age range: 7-11) and 24 typically developing adolescents were matched to the adolescents with SLI (aged range: 12-18). It was not possible to match participants with SLI with TD children on the basis of language age because such TD children would have been too young to perform the writing task.

Both TD participants and participants with SLI were French native speakers and attended mainstream classes in and around Poitiers, France. The children attended primary school, and the adolescents attended middle and high schools. None of them was suffering from any neurological, sensory, relational, or scholastic disorder. The number of participants, their mean ages, and gender proportions are shown in Table 1.

\subsection{Task and procedure}

The writing task consisted of a narrative composition. It was inspired by Berman (2005), Berman, Ragnarsdóttir, and Strömqvist (2002), Berman and Verhoeven (2002) and has been used by Broc et al. (2013) and by Broc, Bernicot, Olive, Favart, and Reilly (2014). The experimenter first introduced herself as a university student carrying out a research project to collect stories on the topic of contentious situations at school. The instructions were provided in French; for this article, we have translated it as follows: "I'm a university student and I have to bring a project to completion. To this end, I have to collect stories on the topic of contentious situations at school. I've already collected a few stories, but I still need some more. Could you help me? Right now, I'm looking for stories about theft or fight situations at primary/middle/high schools (according to the participant's grade level). I assume you've already had to deal with such a situation at primary/middle/high school. So could you tell me that story? I'd like you to write it as a whole, in such a way that I can really understand what happened. If you make any error or if you wish to change anything, just cross it out and keep on writing."

Each participant then wrote the story individually and in a communicative context. This dual situation was unfamiliar at school given that each participant was instructed to compose a story addressed to the experimenter who was physically present throughout the writing process. No time limit was fixed. After a reflection time, all participants began to write spontaneously, and the writing task lasted no more than $15 \mathrm{~min}$. No other instructions were given as regards length, writing speed, or cohesion. Once the text had been composed, the experimenter asked the participant to reread his/her text to avoid any ambiguity in the reading of the written words. 
Table 2

Medians (and standard deviations) of density and diversity of connectives used in children and adolescents with SLI and in typically developing children and adolescents (TD).

\begin{tabular}{|c|c|c|c|c|}
\hline & \multicolumn{4}{|l|}{ Participants } \\
\hline & \multicolumn{2}{|l|}{ SLI } & \multicolumn{2}{|l|}{ TD } \\
\hline & Children & Adolescents & Children & Adolescents \\
\hline Density of connectives & $3.23(4.92)$ & $8.48(4.07)$ & $6.40(3.42)$ & $6.61(3.02)$ \\
\hline Diversity of connectives & $1(0.90)$ & $2(1.78)$ & $1(1.14)$ & $2.5(1.44)$ \\
\hline
\end{tabular}

\subsection{Text analysis}

The narratives were faithfully typed, complying with features of the original products: lower/uppercases, crossed out words, spelling errors, and punctuation marks used. Participants who wrote a text including less than one clause, i.e. a total lack of verb, were removed from the subsequent statistical analysis. This was the case for two children with SLI, who had great difficulties to perform the writing task. Therefore, the four TD children who were matched with these two participants were also removed from the analysis.

Analysis of the text first focused on narrative length, measured in terms of the total number of words produced. Then, the analysis of cohesion focused on the density and diversity of cohesion devices. Density was expressed as the number of each mark used divided by the total number of words in the text, multiplied by 100. Diversity was assessed by the number of different connectives or anaphors used. As regards punctuation marks, only periods and commas were analyzed. On this basis, the dependent variables were Density and Diversity of Connectives, Density of Periods and Commas, and Density and Diversity of Anaphors.

To complete the analyses of diversity, qualitative analyses were performed for connectives and anaphors, which were sorted into categories. Connectives were classified into less versus more differentiated connectives. Subclasses were drawn up on the basis of Favart and Passerault (1999) semantic categorization of connectives, specific to writing acquisition. When drawing up these categories, we sometimes needed to specify the literal form used in French, due to the difficulty to match English and French meanings of these linguistic devices. The less differentiated connectives included the and connective and chronological ones such as then (in French, puis, après, ensuite, et puis, et après). The more differentiated connectives included those that expressed relationships specific to the narrative frame: the adversative connective but; temporal connectives such as then (in French, alors), when, and suddenly; causal connectives such as because and for; consequence connectives such as therefore; and goal connectives such as for and in order to. We also coded spatial connectives (e.g., at the top, at the bottom, on) as descriptive sequences could occur within the stories. Anaphors were coded according the following categories: nominal repetitions (la surveillante/[the supervisor]), nominal substitutions (une bande de jeunes/[a group of young people] was substituted by ces personnes/[these persons]), first name or proper name repetitions, personal pronouns (distinguishing subject, elle/[she]; or object grammatical functions, lui/[her]), and relative pronouns (qui/[who]).

\section{Results}

Statistical analyses were performed with Statistica-7 software. For text length, we ran an ANOVA with group (SLI vs. TD) and age (7-11 vs. 12-18) as between-participants factors. Due to non-normality of the distributions and unequal variance between groups, nonparametric tests were performed on medians of densities and diversities using Mann-Whitney comparison tests to compare (a) children with adolescents within each group and (b) SLI with TD groups at each age.

\subsection{Text length}

Text length in number of produced words significantly differed between the group with SLI and the TD group, $F(1,62)=6.05, p=0.016$, $\eta^{2}=0.09$ : The narratives written by participants with SLI $(M=33.23 ; S D=32.39)$ were shorter than those written by TD participants $(M=53.25$; $S D=35.09)$. The effect of age also was significant, $F(1,62)=15.17, p=0.0002, \eta^{2}=0.20$ : The narratives written by children $(M=28.87 ; S D=20.52)$ were shorter than those of adolescents $(M=61.33 ; S D=38.33)$. The Group x Age interaction was not significant, $F(1,62)<1$.

\subsection{Connectives}

\subsubsection{Effects of age and group}

The density and diversity of connectives are shown in Table 2. In the SLI group, the density significantly increased with age, $U=25, Z=2.3$, $p=0.02, r=0.49$, as well as the diversity, $U=19, Z=2.8, p=0.005, r=0.59$. In the TD group, the connectives used by adolescents also were more diversified than those used by children, $U=123.5, Z=2.8, p=0.005, r=0.42$, but they were not more frequent, $U=232.5, Z=0.18, p=0.85$. The difference between the group with SLI and the TD group was significant only in children. The connectives used by the group with SLI were significantly less frequent, $U=56, Z=1.97, p=0.04, r=0.36$, and also less diversified, $U=57, Z=2, p=0.04, r=0.36$, than the connectives used by the TD group. No significant difference was noticed between scores of adolescents with SLI and TD adolescents.

\subsubsection{Qualitative analysis}

The qualitative analysis of the diversity of connectives was conducted in two steps. We first studied how many categories of connectives participants used and, second, which types of categories were used. The dependent variable Number of Categories was sorted into three levels. The first level identified the percentage of participants who used no connectives, the second level the percentage of participants who used one or two categories in which the connectives were used only to concatenate ideas and the third level the percentage of participants who used at least three categories, i.e. with more diversified narrative relationships. The results are shown in Fig. 1. The majority of children with SLI (60\%) did not use any connective, while that was only the case for $15 \%$ of the TD children. Moreover, children with SLI never used more than two categories of connectives ( $40 \%$ vs. $70 \%$ of TD children who used one or two categories). Finally, $15 \%$ of TD children used at least 

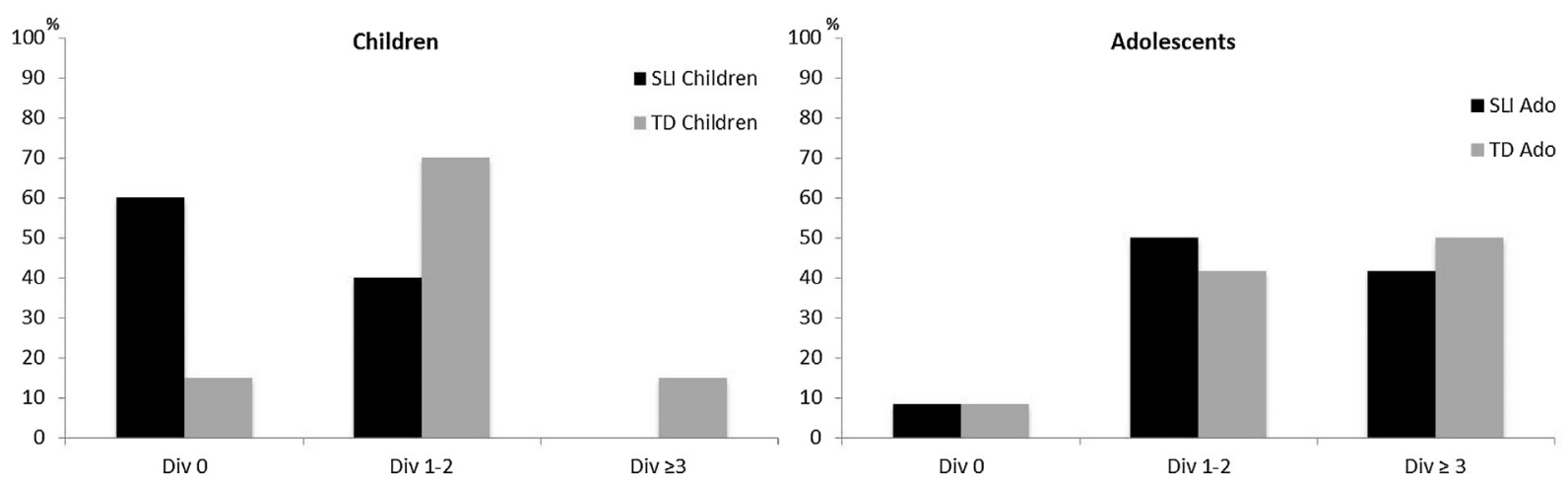

Fig. 1. Percentages of SLI and TD children and adolescents using no, one or two, or at least three different categories of connectives.
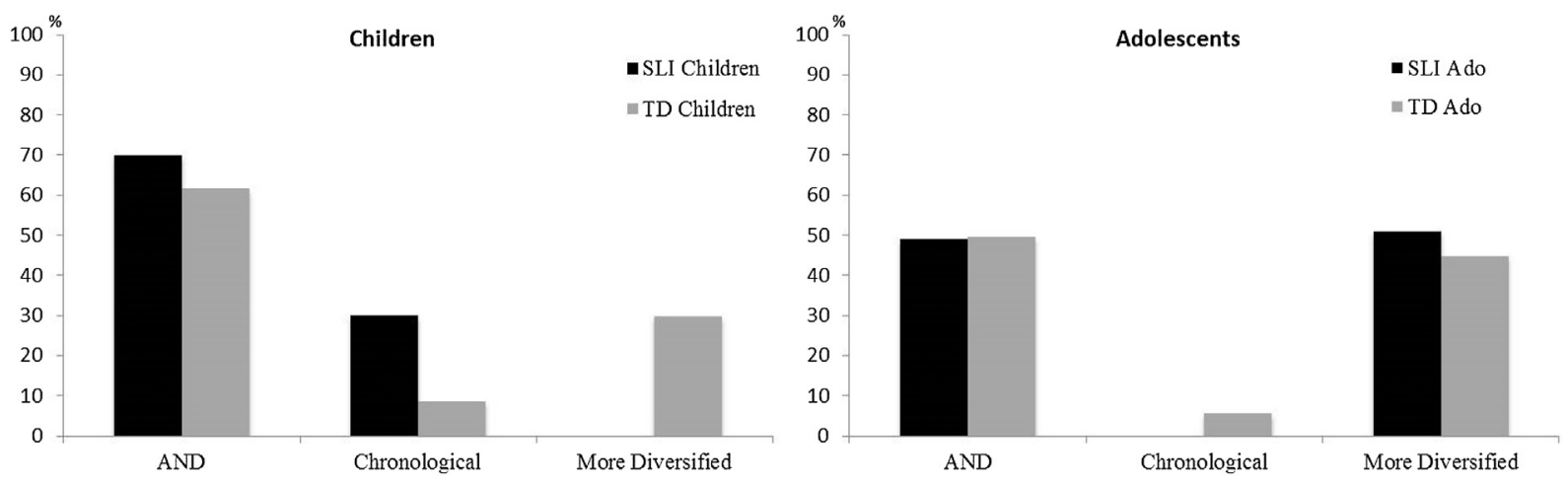

Fig. 2. Percentages of and, chronological, and more diversified connectives (on the total number of connectives) used by SLI and TD children and adolescents.

three categories of connectives. Unlike children, the pattern of diversification of connectives was comparable in adolescents with SLI and TD adolescents: Only $8 \%$ of adolescents with SLI used no connectives, which was the same percentage as in TD adolescents, $50 \%$ of adolescents with SLI used one or two categories (vs. $42 \%$ in TD adolescents), and $42 \%$ of adolescents with SLI used three or more categories (vs. $50 \%$ in TD adolescents).

The dependent variable Variety of Connectives then was sorted according to three categories: and, chronological, and more diversified connectives. Fig. 2 shows the percentages of each variety of connectives on the total of connectives used by children and adolescents. We calculated the percentages of each type of category in relation to the total of connectives used.

In children, the participants with SLI only used the and connective and chronological connectives. The and connective was mainly used in both groups (70\% and $61.7 \%$ of connectives in participants with SLI and TD participants, respectively). The chronological connectives were $30 \%$ of the connectives used by the children with SLI, and $8 \%$ of the connectives used by the TD children. Only TD children used more diversified connectives ( $30 \%$ of the total of connectives) which were not used at all by children with SLI. Focusing on the use by TD children of this latter category, but was mainly used (11\% of connectives), then the temporal $(8 \%)$ and causal (6\%) connectives. Finally, alors and goal connectives amounted to $2 \%$ of the used connectives.

In both groups of adolescents, the use of connectives was comparable as they were quite equally split in two categories: and, which was less frequent in adolescents than in children but still frequently used (49\% in both SLI and TD groups). The more diversified connectives also were quite frequent (51\% of the total in adolescents with SLI and $45 \%$ in TD adolescents). Only $6 \%$ of TD participants used chronological connectives, while participants with SLI used none.

As part of the more diversified connectives category, adolescents with SLI preferentially used causal connectives (15\%), then but and temporal connectives (9\%), goal connectives and alors/then (6\%), and finally spatial connectives (4\%). The pattern in TD adolescents was quite different, with close proportions of use for causal connectives (13\%) and but (11\%), followed by alors (7\%), goal connectives (6\%) and temporal connectives (6\%), and finally a very weak use of spatial connectives (1\%).

\subsection{Punctuation marks}

Only densities of periods and commas were coded. Table 3 shows scores at each age and in each group. In the TD group, the density of comma use significantly increased with age, $U=118, Z=3, p=0.004, r=0.45$, whereas the density of period use remained stable, $U=181.5$, $Z=1.4, p=0.16, r=0.21$. No significant improvement was noticed for punctuation in the SLI group between childhood and adolescence, $U=47.5$, $Z=0.8, p=0.42$ for period and $U=45, Z=1.3, p=.35$ for comma.

The difference between the group with SLI and the TD group was not significant in children, $U=90, Z=0.44, p=0.65$ for period and $U=83.5$, $Z=1, p=0.47$ for comma. In adolescents, the density of comma use was significantly higher in TD participants, $U=77.0, Z=2.3, p=0.02, r=0.38$, whereas no difference was noted for period use, $U=128.5, Z=0.5, p=0.61$. 
Table 3

Medians (and standard deviations) of density of periods and commas used in children and adolescents with SLI and in typically developing children and adolescents (TD).

\begin{tabular}{|c|c|c|c|c|}
\hline & \multicolumn{4}{|l|}{ Participants } \\
\hline & \multicolumn{2}{|l|}{ SLI } & \multicolumn{2}{|l|}{ TD } \\
\hline & Children & Adolescents & Children & Adolescents \\
\hline Density of period & $3.33(6.61)$ & $5.67(3.41)$ & $4.65(3.61)$ & $6.50(3.44)$ \\
\hline Density of comma & $0(0.92)$ & $0(2.60)$ & $0(4.81)$ & $2.95(3.18)$ \\
\hline
\end{tabular}

Table 4

Medians (and standard deviations) of density and diversity of anaphors used in children and adolescents with SLI and in typically developing children and adolescents (TD).

\begin{tabular}{|c|c|c|c|c|}
\hline & \multicolumn{4}{|l|}{ Participants } \\
\hline & \multicolumn{2}{|l|}{ SLI } & \multicolumn{2}{|l|}{ TD } \\
\hline & Children & Adolescents & Children & Adolescents \\
\hline Density of anaphors & $5.88(4.11)$ & $9.03(6.02)$ & $8.33(6.73)$ & $8.22(6.28)$ \\
\hline Diversity of anaphors & $0(.95)$ & $2(1.48)$ & $1(1.04)$ & $3(1.22)$ \\
\hline
\end{tabular}

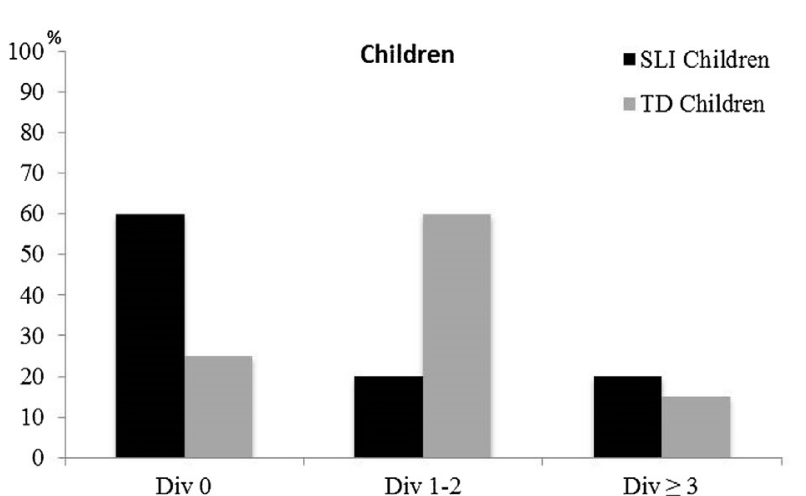

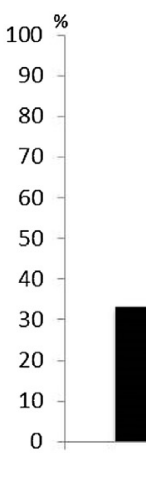

Div 0
Adolescents

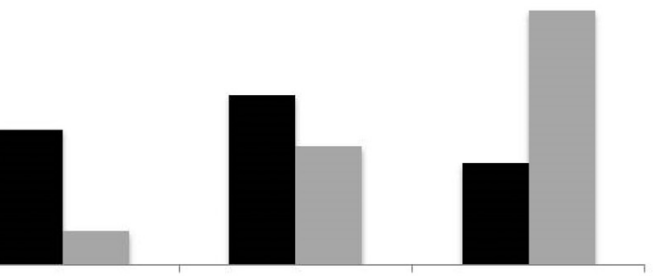

Div 1-2
- SLI A do

- TD Ado

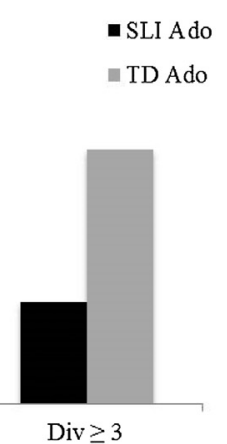

Div $\geq 3$

Fig. 3. Percentages of SLI and TD children and adolescents using no, one or two, or at least three different categories of anaphors.

\subsection{Anaphors}

Anaphors were coded into the following categories: nominal repetition, nominal substitution, first name or proper name repetition, personal pronoun (distinguishing subject or object grammatical functions), and relative pronoun.

\subsubsection{Effects of age and group}

The density and diversity of anaphors are shown in Table 4. In the SLI group, the density of anaphors significantly increased with age, $U=29, Z=2, p=0.04, r=0.42$, unlike the diversity, $U=31, Z=1.9, p=0.059$. Conversely, in the TD group, diversity significantly increased with age, $U=113, Z=3.1, p=0.002, r=0.47$, but not density, $U=221.5, Z=0.4, p=0.66$. It is important to notice that anaphors were very poorly diversified in children with SLI.

The difference between the group with SLI and the TD group was significant only in children. The participants with SLI used less frequent, $U=47.5, Z=2.4, p=0.02, r=0.44$, and also less diversified, $U=53.5, Z=2.2, p=0.03, r=0.40$, anaphors than the TD group. Conversely, in adolescents, the density and diversity of anaphors were not higher in TD participants than in participants with SLI, $U=131.5, Z=0.4, p=0.68$ and $U=98, Z=1.6, p=0.13$, respectively.

\subsubsection{Qualitative analysis}

The qualitative analysis focused on the diversity of anaphors. As for connectives, the analysis was conducted according to the number of categories used and the types of categories used. The dependent variable Number of Categories also was sorted into three levels: the percentage of participants using no anaphors, using one or two categories, and at least three categories. Results of these analyses in children and adolescents are shown in Fig. 3. No anaphors were used by $60 \%$ of children with SLI versus $25 \%$ of TD children. Most of the TD children used one or two types of anaphors (60\%) as compared to $20 \%$ of children with SLI. Finally, $20 \%$ of children with SLI and $15 \%$ of TD children used three categories or more. In adolescents, contrary to connectives, the qualitative patterns of anaphors stayed relatively different in participants with SLI and TD participants: 33\% of adolescents with SLI still did not use any anaphors (vs. $8 \%$ in the TD group). The intermediate score (one or two types) concerned $42 \%$ of adolescents with SLI and $29 \%$ of TD adolescents and only $25 \%$ of adolescents with SLI used at least three types of anaphors (vs. 63\% of TD adolescents).

Next, we analyzed the different types of anaphors used by participants by calculating the percentages of each type of anaphor in relation to the total of anaphors used (see Table 5). In children with SLI only pronouns (personal and relative) were used whereas in TD children the distribution was much more diversified. The use of nominal anaphors was observed only in TD children and interestingly, these children used relatively few relative pronouns. The scores of relative pronouns in children with SLI ( $45.45 \%$ vs. $11.94 \%$, in TD children) might seem quite 
Table 5

Percentages of categories of anaphors used in children and adolescents with SLI and in typically developing children and adolescents (TD).

\begin{tabular}{|c|c|c|c|c|}
\hline & \multicolumn{4}{|c|}{ Participants } \\
\hline & \multicolumn{2}{|l|}{ SLI } & \multicolumn{2}{|l|}{ TD } \\
\hline & Children & Adolescents & Children & Adolescents \\
\hline Nominal repetitions & - & $18.52 \%$ & $5.97 \%$ & $6.25 \%$ \\
\hline Nominal substitution & - & $14.81 \%$ & $7.46 \%$ & $17.5 \%$ \\
\hline Name repetition & - & - & $22.39 \%$ & $11.25 \%$ \\
\hline Subject personal pronoun & $27.27 \%$ & $35.18 \%$ & $37.31 \%$ & $28.12 \%$ \\
\hline Object personal pronoun & $27.27 \%$ & $12.96 \%$ & $14.92 \%$ & $21.25 \%$ \\
\hline Relative & $45.45 \%$ & $18.51 \%$ & $11.94 \%$ & $15.63 \%$ \\
\hline
\end{tabular}

surprising. A more fine-grained inspection showed, however, that the relative pronoun qui/who was used by $80 \%$ of children with SLI as part of left dislocations, such as "c'est _- qui"|"it is _. who"

In adolescence, the pattern of anaphors was comparable between the SLI and TD participants. Personal and relative pronouns were used at a similar frequency by participants with SLI and by TD participants. Moreover, we did not notice any occurrence of relative pronoun as left dislocation in adolescents with SLI. As regards nominal anaphors, only the TD adolescents used first name repetitions; the proportion of nominal repetitions was slightly higher in adolescents with SLI than in TD adolescents; but the two groups of adolescents used at a similar rate nominal substitutions.

\section{Discussion}

The present study investigated how children and adolescents with SLI manage cohesion in written narratives by comparing the participants with SLI to chronological age-matched, typically developing peers. Participants all attended mainstream classes: children in elementary schools and adolescents in middle and junior high schools. Specifically, we quantitatively and qualitatively analysed connectives, punctuation marks, and anaphors in written narratives. Cohesion devices are crucial indicators of the writer's capacity to consider the overall meaning of the text. As these devices link ideas in a text, they serve as key processing instructions to improve the addressee's comprehension, so their use is in direct relation to pragmatic abilities. On this basis, we chose a communicative narrative situation, which pragmatically engaged participants in the task so that they could take into account the addressee as much as possible. This situation seemed appropriate to support linguistic coding at the level of text generation, which is particularly deficient in participants with SLI (Dockrell et al., 2009).

The core of this research was to compare the scores of four different groups: children with SLI, adolescents with SLI, TD children and TD adolescents. To answer to the first aim, we compared performances of participants with SLI and of TD participants. First, texts were shorter in the two groups of participants with SLI (children and adolescents) compared to their peers, attesting to their overall difficulties with text generation. In spite of their well-established management of periods, the children with SLI failed in their use of both connectives and anaphors: both density and diversity were weaker than in TD children. Most of the children with SLI did not use a connective and/or anaphor, none of them used specific connectives, and their marking of narrative relationships was restricted to the undifferentiated and and/or chronological connectives. By contrast, almost a third of the TD children explicitly expressed adversative, temporal, or causal relationships specific to narratives. The way children with SLI managed cohesion in this communicative writing situation was comparable to the management of cohesion attested by studies on narrative speech, with a lack of differentiation of connectives (Bernard-Barrot \& Géhard, 2003), series of sentences being commonly linked with the connective and (De Weck \& Rosat, 2003), and no improvement in connectives diversification between the ages of 7 and 12 years old (Hilaire-Debove \& Roch, 2012).

As regards anaphors, previous results in narrative speech showed that children with SLI persistently use nominal repetitions (HilaireDebove \& Roch, 2012). Unexpectedly, in writing, they only used pronouns, half relative and half personal, whereas TD children used about half varied nominal references and half pronouns. Nevertheless, a more fine-grained analysis indicated that a high majority of relative pronouns (80\%) were used within left dislocations. These specific structures were observed in previous studies investigating the oral production of children with SLI (De Weck \& Jullien, 2013; Jullien, 2008) and they are the signs of an immature referential management. According to Leonanduzzi (2008), the relative pronoun is in that case included in a split sentence in order to put the emphasis on the referent. The aim and the function of such forms are mainly pragmatic and they are used to stress the focus on the referent. Our results show comparable outputs in writing, perhaps because of the communicative situation we set up.

The second aim was to compare the two age groups (children and adolescents) in participants with SLI and in TD participants. Children produced shorter narratives than adolescents and the difference was comparable in the group with SLI and in the TD group. Moreover, the densities of connectives and anaphors were higher in adolescents with SLI than in children with SLI, as a majority of the latter did not use any connectives and/or anaphors. Diversity is indeed more relevant than density to assess cohesion (see Bernard-Barrot \& Géhard, 2003 or Favart \& Passerault, 1995 for connectives; Decool-Mercier and Akinci (2010) or Karmiloff-Smith, 1985, 1992 for anaphors).

Results on diversity were very different compared to results on density. As regards connectives, adolescents used more diversified connectives than children in both the group with SLI and the TD group. By contrast, anaphors and punctuation marks were more diversified in adolescents in the TD group only. Most of the TD adolescents used at least three different types of anaphors, and the density of commas also was higher in this group compared to TD children. As in previous studies (Favart \& Passerault, 2000), the period was predominantly used and strongly implemented from the beginning of narrative writing, while the implementation of the comma was postponed and only developed in TD adolescents. In line with Schneuwly (1988), only TD adolescents were able to manage the punctuation marks at a textual level and diversified the strength of breakings between textual units in order to appropriately clarify the textual content for the addressee.

The most surprising and noteworthy result of this study referred to the performance of adolescents with SLI. Whereas the use of connectives and anaphors was impaired in children with SLI, their use by adolescents with SLI was close to the one of their TD peers: They used as many connectives and anaphors, which were as many diversified. This outcome differs from Dockrell et al.'s study (2009), in which huge difficulties in writing narrative remained and even increased for participants with SLI throughout adolescence relative to standardized norms.

One possible explanation for the relatively good performance in the management of cohesion of our sample of adolescents with SLI might lie in the specific instruction we provided for the narrative composition and in the communicative interaction we set up. Indeed, because 
individuals with SLI have pragmatic abilities (Katsos, Roqueta, Clemente Estevan, \& Cummins, 2011; Wetherell, Botting, \& Conti-Ramsden, 2007), they may have taken advantage of this type of situation. Previous work by Broc et al. (2013, 2014) demonstrated that spelling errors are less dominant in children and adolescents with SLI in a communicative context than in a more evaluative situation (i.e., dictation). In comparison, Dockrell et al. (2009) set up a more regular writing situation, as their participants were instructed to write a letter describing their ideal house. The ability to take into account the addressee is crucial for an accurate management of cohesion, but this is a difficult task for young writers insofar as it requires the capacity to activate the representation of the addressee in working memory. According to McCutchen (1986) and Martlew (1983), taking into account the addressee can only be effective in TD students at the age of middle school. The good performance of the adolescents with SLI may indicate that they also indeed took into account the addressee. In line with Broc et al. (2013, 2014), a communicative narration could enable individuals with SLI to fully express their potential. This is only possible insofar as students can take into account the addressee in writing, and this capacity seemed to be effective in both middle school students with SLI and TD students. This finding is worth taking into account, in particular in educational and/or remediation contexts, as it suggests that when children with SLI are provided with appropriate support, their writing abilities may improve until adolescence.

In sum, only the system of punctuation marks was affected in both SLI children and adolescents. This is certainly due to the belated development of this cohesion system, whose textual management in TD students is not completely reached before the age of 14 years old (Schneuwly, 1988). Except for punctuation, from middle school, students with SLI were able to manage cohesion as well as TD students, in spite of their repeated oral language disorders. We agree with Dockrell et al. (2009) who interpret the nature of the writing difficulties in terms of lack of language and literacy resources, and our research further indicates that participants with SLI can deal with some aspects of writing when pragmatic cues are provided in the writing situation.

\section{References}

Apotheloz, D. (1989). Aspects cognitifs des procédures de la cohésion textuelle [Cognitive aspects of textual cohesion]. Duisburg: L.A.U.D.

Bartlett, E. J., \& Scribner, S. (1982). Text and content: An investigation of referential organization in children's written narratives. In C. H. Frederiksen, \& J. F. Dominic (Eds.), Writing: The nature, development, and teaching of written communication, vol.2: writing: Process, development and communication (pp. 153-168). Hillsdale, NJ: Lawrence Erlbaum Associates.

Berman, R. A., \& Verhoeven, L. (2002). Crosslinguistic perspectives on developing text-production abilities in speech and writing. Written Language and Literacy, 5, 1-44. http://dx.doi.org/10.1075/wll.5.1

Berman, R. A., Ragnarsdóttir, H., \& Strömqvist, S. (2002). Discourse stance. Written Language and Literacy, 5, $255-290$. http://dx.doi.org/10.1075/wll.5.2.06ber

Berman, R. A. (2005). Introduction: Developing discourse stance in different text types and languages. Journal of Pragmatics, 37, $105-124$. http://dx.doi.org/10.1016/j.pragma.2004.08.003

Bernard-Barrot, C., \& Géhard, S. (2003). Le récit oral: Comparaison d'enfants présentant une dysphasie et d'enfants sans troubles du langage oral. Mesures linguistiques et narratives [Oral narratives: Comparison of children with dysphasia and of children without language difficulties. Linguistic and narrative measures]. Lyon, France: Mémoire d'orthophonie. № 1216.

Berninger, V. W., \& Swanson, H. L. (1994). Modifying Hayes and Flower's model of skilled writing to explain beginning and developing writing. In J. S Carlson, \& E. C. Butterfly (Eds.), Advances in cognition and educational practice. vol. 2: children's writing: Toward a process theory of the development of skilled writing (pp. 57-81). Greenwich, CT: J.A.I. Press.

Bishop, D. V., \& Clarkson, B. (2003). Written Language as a window into residual language deficits: A study of children with persistent and residual speech and language impairments. Cortex, 39, 215-237. http://dx.doi.org/10.1016/s0010-9452(08)70106-0

Bishop, D. V. M. (1992a). The underlying nature of specific language impairment. Journal of Child Psychology and Psychiatry and Allied Disciplines, 33, 3-66. http://dx.doi.org/10.1111/j. 1469-7610.1992. tb00858. x

Bishop, D. V. M. (1992b). The underlying nature of specific language impairment. Journal of Child Psychology and Child Psychiatry, 3, 1-64. http://dx.doi.org/10.1111/j. 1469-7610.1992. tb00858. x

Broc, L., Bernicot, J., Olive, T., Favart, M., Quémart, P., Reilly, J., et al. (2013). Lexical spelling in children and adolescents with Specific Language Impairment: Variations in different writing situations. Research in Developmental Disabilities, 34, 3253-3266. http://dx.doi.org/10.1016/j.ridd.2013.06.025

Broc, L., Bernicot, J., Olive, T., Favart, M., Reilly, J., Quémart, P., et al. (2014). Évaluation de l'orthographe des élèves dysphasiques en situation de narration communicative: Variations selon le type d'orthographe, lexicale versus morphologique [Assessment of lexical and morphological spelling in young SLI children with a communicative narrative task]. European Review of Applied Psychology, 64, 307-321. http://dx.doi.org/10.1016/j.erap.2014.09.004

Chevrie-Muller, C., \& Plazza, M. (2001). Nouvelles Epreuves pour l'Examen du Langage (N-EEL) [New tasks for language assessment]. Paris: Editions du Centre de Psychologie Appliquée.

Chevrie-Muller, C., Simon, A. M., \& Fournier, S. (1997). Batterie langage oral et ecrit Mémoire attention (L2MA) [Test oral and written language, memory, attention]. Paris: Editions du Centre de Psychologie Appliquée.

Cordewener, K. A. H., Bosman, A. M. T., \& Verhoeven, L. (2012). Characteristics of early spelling of children with specific language impairment. Journal of Communication Disorders, 45, 212-222. http://dx.doi.org/10.1016/j.jcomdis.2012.01.003

De Cat, C. (2004). A fresh look at how children encode new referents. International Review of Applied Linguistics, 42, $111-127$. http://dx.doi.org/10.1515/iral.2004.005

De Weck, G., \& Jullien, S. (2013). How do French-speaking children with specific language impairment first mention a referent in story telling? Between reference and grammar. Journal of Pragmatics, 56, 70-87. http://dx.doi.org/10.1016/j.pragma.2013.05.009

De Weck, G., \& Rosat, M. F. (2003). Troubles dysphasiques. Comment raconter, relater, faire âgir à l'âge préscolaire [Dysphasics' difficulties: How to tell, recount, and make acting at preschool ages]. Paris: Masson.

Decool-Mercier, N., \& Akinci, M. A. (2010). Le fonctionnement des anaphores dans les textes oraux et écrits en francais d'enfants bilingues et monolingues [The functioning of anaphors in oral and written texts of monolingual and bilingual children]. In 2ème Congrès Mondial de Linguistique Française. Paris: EDP Sciences [p. 102].

Dockrell, J. E., \& Lindsay, G. (2000). Meeting the needs of children with specific speech and language difficulties. European Journal of Special Needs Education, 15, 24-41. http://dx.doi.org/10.1080/088562500361682

Dockrell, J. E., Lindsay, G., Connelly, V., \& Mackie, C. (2007). Constraints in the production of written texts in children with specific language impairments. Exceptional Children, 73, 147-164 [1177/001440290707300202].

Dockrell, J. E., Lindsay, G., \& Connelly, V. (2009). The impact of specific language impairments on adolescents' written texts. Exceptional Children, 75, 427-446. http://dx.doi.org/10.1177/001440290907500403

Favart, M., \& Passerault, J.-M. (1995). Evolution du rôle fonctionnel des connecteurs et de la planification du récit écrit chez les enfants de 7 à 11 ans [Changes in functional role of connectives and of planning in children from 7 to 11]. Revue De Phonétique Appliquée, 198-212 [115-116-117].

Favart, M., \& Passerault, J.-M. (1996). Functionality of cohesion devices in the management of local and global coherence: Two studies in children's written production of narratives. In R. Rijlaarsdam, H. van den Berg, \& T. Jechle (Eds.), Theories, models and methodologies in writing (pp. 349-365). Amsterdam: Amsterdam University Press. 
Favart, M., \& Passerault, J.-M. (1999). Aspects textuels du fonctionnement et du développement des connecteurs: Approche en production [Textual aspects of functioning and development of connectives: Approach in language production]. L'Année Psychologique, 99, $149-173$. http://dx.doi.org/10.3406/psy.1999.28552

Favart, M., \& Passerault, J.-M. (2000). Aspects fonctionnels du point et de la virgule dans l'évolution de la planification du récit écrit [Functional aspects of full stops and commas in changes of planning of written narratives]. Enfance, 2, 187-205. http://dx.doi.org/10.3406/enfan.2000.3176

Favart, M. (2005). Les marques de cohésion: Leur rôle fonctionnel dans l'acquisition de la production écrite de texte [Cohesion devices: Their functional role in the acquisition of text production]. Psychologie Française, 50-53, 305-322. http://dx.doi.org/10.1016/j.psfr.2005.05.006

Fayol, M. (1997). On acquiring punctuation: A study of written French. In J. Costermans, \& M. Fayol (Eds.), Processing interclausal relationships: Studies in the production and comprehension of Text. Mahwah, NJ: Lawrence Erlbaum Associates.

Fey, M. E., Catts, H. W., Proctor-Williams, K., Zhang, X., \& Tomblin, J. B. (2004). Oral and written composition skills of children with language impairments. Journal of Speech, Language, and Hearing Research, 47, 1301-1318. http://dx.doi.org/10.1044/1092-4388(2004/098)

Fraser, B. (1999). What are discourse markers? Journal of Pragmatics, 31, 931-952. http://dx.doi.org/10.1016/s0378-2166(98)00101-5

Freed, J., Adams, C., \& Lockton, E. (2011). Literacy skills in primary school-aged children with pragmatic language impairment: A comparison with children with specific language impairment. International Journal of Language and Communication Disorders, 46, $334-347$. http://dx.doi.org/10.3109/13682822.2010.500316

Gernsbacher, M. A. (1989). Mechanisms that improve referential access. Cognition, 32, 99-156. http://dx.doi.org/10.1016/0010-0277(89)90001-2

Gillam, R. B., \& Johnston, J. R. (1992). Spoken and written language relationships in language/learning-impaired and normally achieving school-age children. Journal of Speech and Hearing Research, 35, 1303-1315. http://dx.doi.org/10.1044/jshr.3506.1303

Hickmann, M. (2004). Coherence, Cohesion, and Context. Some comparative perspectives in narrative development. In S. Strömqvist, \& S. L. Verhoeven (Eds.), Relating events in narrative: Typological and contextual perspectives (pp. 291-306). Mahwah, NJ: Lawrence Erlbaum Associates.

Hilaire-Debove, G., \& Roch, D. (2012). La conduite de récit chez l'enfant dysphasique [Narratives in children with dysphasia]. Les Entretiens De Bichat, $179-195$

Jullien, S. (2008). Constructions syntaxiques et discours: Les introductions de référents dans les narrations produites par des enfants présentant des troubles spécifiques du langage oral et des enfants tout-venant [Syntactical constructions and discourse: The introduction of referents in the narratives produced by children with and without SLI]. Travaux Neuchâtelois De Linguistique, 48, 7-24.

Karmiloff, K., \& Karmiloff-Smith, A. (2003). (1st ed.). Comment les enfants entrent dans le langage How children enter in language] (2001) Paris: Retz.

Karmiloff-Smith, A. (1985). Language and cognitive processes from a developmental perspective. Language and Cognitive Processes, $1,61-85$. http://dx.doi.org/10.1080/01690968508402071

Karmiloff-Smith, A. (1992). Beyond modularity: A developmental perspective on cognitive science. Cambridge, MA: MIT Press.

Katsos, N., Roqueta, C. A., Clemente Estevan, R. A., \& Cummins, C. (2011). Are children with specific language impairment competent with the pragmatics and logic of quantification? Cognition, 19, 43-57. http://dx.doi.org/10.1016/j.cognition.2010.12.004

Kern, S. (2000). Junction and segmentation in French children's narratives. Psychology of Language and Communication, 4, 47-63.

Khomsi, A., Khomsi, J., Pasquet, F., \& Parbeau Guéno, A. (2007). Bilan Informatisé de Langage Oral au cycle 3 et au Collège (BILO-3C) [Computerized assessment of oral Language for 8-10 years old children, and at middle school]. Paris: Editions du Centre de Psychologie Appliquée.

Khomsi, A., Khomsi, J., \& Pasquet, F. (2007). Bilan Informatisé de Langage Oral au cycle 2 (BILO-2) [Computerized assessment of oral language for 5-7 years old children]. Paris: Editions du Centre de Psychologie Appliquée.

Lambert, M. (2003). Cohésion et connexité dans des récits d'enfants et d'apprenants polonophones du français [Cohesion and connexity in the written narratives of children and of Polish learners of French]. Marges Linguistiques, 5, 106-121.

Leonanduzzi, L. (2008). Dislocations à gauches et antépositions: Des variantes en distribution complémentaire? [Left dislocations and antepositions: Variants in complementary distribution.] Actes du Congrès de la SAES. pp. 121-142. Saint-Etienne, France: Publications de l'Université de Saint-Etienne.

Leonard, L. B. (2014). Children with specific language impairment (2nd ed.). Cambridge, MA: MIT Press.

Louwerse, M. M., \& Mitchell, H. H. (2003). Towards a taxonomy of a set of discourse markers in dialog: A theoretical and computational linguistic account. Discourse Processes, 35, 199-239. http://dx.doi.org/10.1207/S15326950DP3503_1

Mackie, C., \& Dockrell, J. E. (2004). The nature of written language deficits in children with SLI. Journal of Speech and Hearing Research, 47, 1469-1483. http://dx.doi.org/10.1044/1092-4388 2004/109

Martlew, M. (1983). The psychology of written language: Developmental and educational perspectives. Chichester, UK: John Wiley and sons.

McCutchen, D. (1986). Domain knowledge and linguistic knowledge in the development of writing ability. Journal of Memory and Language, 25, 431-444.

McCutchen, D. (1996). A capacity theory of writing: Working memory in composition. Educational Psychology Review, 8, $299-325$. http://dx.doi.org/10.1016/0749-596X(86)90036-7

Moeschler, J. (2002). Connecteurs, encodage conceptuel et encodage procédural [Connectives, conceptual encoding and procedural encoding]. Cahiers De Linguistique Française, 24, 265-292.

Passerault, J.-M. (1991). La ponctuation: Recherches en psychologie du langage [Punctuation: Research in Psychology of language]. Pratiques, 70, 85-106.

Pellegrini, A. D., Galda, L., \& Rubin, D. L. (1984). Context in text: The development of oral and written language in two genres. Child Development, 55, 1549-1555. http://dx.doi.org/10.2307/1130025

Reichler- Beguelin, M. J. (1988). Anaphore, cataphore et mémoire discursive [Anaphor: Cataphor and discursive memory]. Pratiques, 57, 15-43.

Rutter, P., \& Raban, B. (1982). The development of cohesion in children's writing: A preliminary investigation. First Language, 3, 63-75. http://dx.doi.org/10.1177/014272378200300704

Schneuwly, B. (1988). Le langage écrit chez l'enfant [The written language of children]. Paris: Delachaux \& Niestlé.

Scott, C., \& Windsor, J. (2000). General language performance measures in spoken and written discourse produced by school-age children with and without language learning disabilities. Journal of Speech, Language and Hearing Research, 43, 324-339. http://dx.doi.org/10.1044/jslhr.4302.324

Snowling, M., Bishop, D. V. M., \& Stothard, S. E. (2000). Is Preschool language impairment a risk factor for dyslexia in adolescence? Journal of Child Psychology and Psychiatry, 41, 587-600. http://dx.doi.org/10.1017/s0021963099005752

Stoye, H. (2013). Les connecteurs contenant des prépositions en français: Profils sémantiques et pragmatiques en synchronie et diachronie [Connectives containing prepositions in French: Pragmatique and semantic profiles in synchrony and diachrony]. Berlin: De Gruyter.

Wechsler, D. (1996). Echelle d'intelligence pour enfants (3ème édition) [Intelligence scale for children, 3rd edition]. Paris: Editions et Applications Psychologiques.

Wetherell, D., Botting, N., \& Conti-Ramsden, G. (2007). Narrative skills in adolescents with a history of SLI in relation to Non-verbal IQ scores. Child Language, Teaching and Therapy, 23, 95-113. http://dx.doi.org/10.1080/13682820601056228

Williams, G. J., Larkin, R. F., \& Blaggan, S. (2013). Written language skills in children with specific language impairments. International Journal of Language and Communication Disorders, 48, 160-171. http://dx.doi.org/10.1111/1460-6984.12010

van Weerdenburg, M., Verhoeven, L., Bosman, A., \& van Balkom, H. (2011). Predicting word decoding and word spelling development in children with Specific Language Impairment. Journal of Communication Disorders, 44, 392-411. http://dx.doi.org/10.1016/j.jcomdis.2010.12.002 